\title{
COLONIALISMO E ACUMULAÇÃO POR ESPOLIAÇÃO: PANORAMAS CONCEITUAIS E O CONTEXTO DE TERRAS NO BRASIL
}

\section{Luís Felipe Perdigão de Castro ${ }^{1}$}

Resumo: O artigo debate, em pesquisa bibliográfica, a inserção da terra sob a lógica colonial, enfatizando os sentidos da violência e da expropriação de terras e sua conexão com processos capitalistas posteriores. Objetiva-se contextualizar a colonização como um dos marcos iniciais de apropriação privada de recursos naturais, especialmente estruturado com o sesmarialismo e a Lei de Terras, de 1850. O pano de fundo do estudo é a concentração de terras como traço determinante de exclusão de direitos, destacando-se a implantação do sesmarialismo (15301824) e, após a independência (1822), a Lei $\mathrm{n}^{\circ}$ 601, de 18 de setembro de 1850 ("Lei de Terras").

Palavras-chave: Conflitos por terra; Colonialismo; Capitalismo; Acumulação por espoliação; Brasil

\section{THE COLONIALISM AND ACCUMULATION BY DISPOSSESSION: CONCEPTUAL PANORAMAS AND THE LAND CONTEXT IN BRAZIL}

\begin{abstract}
The article discusses, in bibliographic research, the insertion of land under the colonial logic, emphasizing the meanings of violence and land expropriation and its connection with later capitalist processes. The objective is to contextualize colonization as one of the initial milestones for private appropriation of natural resources, especially structured with sesmarialism and the Land Law of 1850. The background of the study is the concentration of land as a determining feature of exclusion of rights, highlighting the implantation of sesmarialism (1530-1824) and, after independence (1822), Law No. 601, of September 18, 1850 ("Land Law").
\end{abstract}

Keywords: Land conflicts; Colonialism; Capitalism; Accumulation by dispossession; Brazil

\section{INTRODUÇÃO}

A apropriação privada e os conflitos dela decorrentes, iniciados pelo colonialismo, levaram àquilo que Souza Filho (2013) definiu como a usurpação de terras e de gentes. É fundamental colocar a dinâmica socioeconômica em perspectiva sociohistórica. A apropriação de terras vem ocorrendo há séculos, incluindo novas lógicas de expulsão (SASSEN, 2010; 2016), expropriações violentas (FAJARDO, 2009) e de "accumulation by dispossession" (HARVEY, 2003), expressão traduzida neste trabalho como acumulação por despossessão, que se inserem em ciclos de acumulação de capital.

\footnotetext{
${ }^{1}$ Doutor em Ciências Sociais, pela Universidade de Brasília. Professor e Coordenador de Direito (UNICEPLAC e UNIDESC). Pesquisador do grupo de pesquisa BICAS (UnB).
} 
Aproximando passado e presente, o artigo debate, com base em pesquisa bibliográfica, a inserção da terra sob a lógica colonial, enfatizando os sentidos da violência e da expropriação de terras e sua conexão com processos capitalistas posteriores. Objetiva-se contextualizar a colonização como um dos marcos iniciais de apropriação privada de recursos naturais, especialmente estruturado com o sesmarialismo e a Lei de Terras, de 1850.

No primeiro tópico descreve-se o cenário político atual, apontando o recrudescimento do conflito e da violência, para entender que há uma trajetória histórica mais longa e permanente, isto é, a latência de um conflito que não se exaure apenas na noção de disputa por terras. A força do termo "conflito" remete à existência de classes e categorias que se estruturam em torno de antagonismos e identidades.

No segundo tópico particulariza-se a análise sobre como a propriedade sobre as terras surgiu, enquanto privilégio concedido a grupos restritos, privados e ligados ao poder político. A concentração de terras adquiriu desde então o traço determinante de exclusão de direitos, destacando-se o ponto de partida na implantação do sesmarialismo (1530-1824) e, após a independência (1822), o aprofundamento trazido pela Lei ${ }^{\circ} 601$, de 18 de setembro de 1850, ou simplesmente, a "Lei de Terras".

Por fim, o terceiro tópico enfatiza relações de continuidade entre o passado e o presente, destacando o caráter permanente da acumulação primitiva, sob diferentes roupagens, compondo aquilo que Harvey (2003) definiu como a acumulação por despossessão.

\section{CONFLITO E VIOLÊNCIA: ESTRUTURAS SOCIOHISTÓRICAS DO BRASIL}

Conflito e violência são traços estruturantes da sociedade brasileira e da forma de atuar de suas instituições. As instituições podem ser entendidas como as regras do jogo em sociedade, colocando limites para "moldar as interações humanas" (NORTH, 1990, p. 03). Regem, organizam e dão significado, fazendo com que os discursos, grupos, valores ou estruturas hegemônicas importem na "criação de padrões de comportamento e de regras de inserção e exclusão" (MELLO, 2018, p. 25). Dentro dessa dinâmica, continuam ativos os processos históricos de exclusão e concentração, como também as respostas em formas de lutas e resistências sociais (CASTRO, 2019).

No últimos anos do século XXI, os processos históricos de exclusão e concentração se tornaram bastante visíveis no Brasil, sob o fio condutor de um grande retrocesso 
democrático e constitucional, composto por uma série de desconstruções, marcadamente pós2016, e que consistiram na desarticulação e destruição profunda de políticas públicas e legislações sociais e ambientais, consolidadas ao longo das últimas décadas. ${ }^{2}$

Na prática, o cenário político e econômico, que já se agravara com o governo de Michel Temer (2016-2019), assumiu patamares de verdadeira tragédia humanitária, social e ambiental cognominada de governo Jair Bolsonaro (2019-atual). Aplicando uma cartilha contraditória, o governo Bolsonaro adotou um discurso ultraliberal, com elementos nacionalistas, populistas e de extrema direita, alinhando-se automaticamente ao então presidente norte-americano, Donald Trump. Não obstante essa completa dissonância com a tradição diplomática brasileira, o conservadorismo do governo se associou à hostilidade pública à imprensa e às universidades, além da frequente exclusão de categorias sociais a que se negam abertamente direitos, como os territoriais a povos indígenas e comunidades quilombolas. Avançando contra os marcos constitucionais de 1988 e ao contrário de promessas eleitorais, vem ocorrendo o aparelhamento de órgãos de Estado (como a Polícia Federal e a Procuradoria-Geral da República, para não citarmos o caso da Fundação Palmares), além de movimentos contrários às evidências científicas mundiais na área de saúde, meio ambiente e de combate à pandemia. ${ }^{3}$

Como síntese da tragédia, uma das faces mais visíveis é o agravamento de conflitos e respostas estatais violentas aos povos e comunidades tradicionais. Em campo político diametralmente oposto, permanece vivo o debate sobre a posse e uso da terra e, de forma geral, sobre a apropriação e controle dos bens da natureza. Mais recentemente, mobilizações e eventos como o "2 2 Seminário Terra e Território: Diversidade e Lutas", ocorrido virtualmente no dia 15/05/2020, denunciaram os impactos negativos do governo Jair Bolsonaro (sem partido) contra organizações e lideranças ligadas à luta por terra, pela preservação do meio

\footnotetext{
${ }^{2}$ No Brasil, esse ciclo progressista foi interrompido por uma crise política e econômica, causada tanto pelas pressões do imperialismo estadunidense e seus aliados para destruir a esquerda latinoamericana, quanto pelas limitações inerentes ao neodesenvolvimentismo (FUSER, 2018). A crise brasileira, ainda sem solução, desaguou em um golpe midiático-parlamentar em 2016, e na vitória de narrativas "antipolítica" de Bolsonaro em 2018 (BOITO, 2020). Bolsonaro acabou sendo eleito por uma "coalizão de conveniências" (NOBRE, 2020), envolvendo setores conservadores católicos, mas especialmente de evangélicos neopentecostais, forças armadas, concertação política do agronegócio, direita "tradicional" e neoliberal, capital financeiro e neofascistas. (SAUER, LEITE e TUBINO, 2020, p. 287)

${ }^{3}$ A outra estratégia governamental de ataques a direitos (sociais, trabalhistas, ambientais, inclusive aos direitos humanos e direitos das minorias) se aprofundou, ou se tornou mais explícita nesse contexto de crise. Explicitando uma "guerra cultural" e uma "lógica militar", as ações governamentais, buscando confrontos e justificando ações com base no "combate ao inimigo", só aprofundam a crise social e política. A pior expressão desse aprofundamento é a total falta de empatia do próprio Bolsonaro com o sofrimento decorrente da crise, pois não há uma única referência pública de conforto às mais de 80 mil vidas perdidas devido à covid-19. A pandemia e as consequentes crises econômica e social forçaram mudanças políticas. A pauta do Governo Bolsonaro mudou, inclusive procurando escudos e proteção das investigações em andamento no Judiciário e possivelmente no Legislativo, formando alianças com partidos e parlamentares do Centrão. Na direção contrária às promessas de campanha, o governo se alia ao que ele próprio denominou de "velha política" distribuindo cargos na Esplanada em troca de apoio e proteção, especialmente contra investigações envolvendo membros do governo - se não o próprio Bolsonaroem ataques à democracia e às instituições de Estado e disseminação de fake News (SAUER, LEITE e TUBINO, 2020, p. 286).
} 
ambiente, por direitos à cidadania, cultura e identidades sociais (BARBOSA, 2020; BERNARDES, 2020).

O referido seminário reuniu cerca de 150 representantes de povos e comunidades tradicionais, mostrando conexões de agendas e reivindicações dos povos dos campos, das águas e das florestas. Por exemplo, organizações como a Confederação Nacional dos Trabalhadores da Agricultura Familiar (Contraf) reforçaram a importância e debate sobre os camponeses e as dificuldades atuais. O Movimento de Mulheres Camponesas (MMC) vem destacando impactos ainda maiores, em contexto no qual apenas 5\% das terras produtivas estão nas mãos das mulheres e como a falta de registros agrava o acesso desigual a recursos governamentais. A Coordenação das Organizações Indígenas da Amazônia Brasileira (Coiab) denunciou que cerca de 400 indígenas foram contaminados e 90 morreram por coronavírus, até maio de 2020. O Movimento pela Soberania Popular na Mineração (MAM) observou que a mineração foi considerada pelo governo uma das atividades essenciais de trabalho e, por isso, foi vedada a quarentena ao setor.

Manobras políticas como essa e muitas outras, como a Resolução 500/20 do Conselho Nacional do Meio Ambiente (liberando a exploração de áreas de restingas e manguezais) viabilizaram que grandes empresas explorassem minério e outros recursos naturais sem fiscalização, durante a pandemia. Enquanto isso, no meio rural, grandes produtores receberam R\$ 230 bilhões no Plano Safra 2019/2020 do Governo Federal, ao passo que os agricultores familiares, assentados e povos e comunidades tradicionais receberam menos de R\$30 bilhões (BARBOSA, 2020; BERNARDES, 2020). As cifras de desigualdade entre agronegócio e agricultura familiar não são apenas números que revelam o compromisso político do atual governo. Em relação à agenda da terra, Leite e colegas (2019) caracterizaram quatro grupos que disputam espaço político no interior do governo Bolsonaro. ${ }^{4}$

$\mathrm{O}$ acesso desigual a recursos se insere na lógica de fatores que, como a apropriação privada de terras, concentração e exclusão fundiária, produzem e pressionam, bem como

\footnotetext{
${ }^{4}$ Esses são: i) uma fração do capital financeiro na agricultura, descolado da concertação do agronegócio, que propôs o lançamen to de uma golden share para a gestão de terras públicas; ii) setores hegemônicos do agronegócio, capitaneados pela Frente Parlamentar da Agricultura e pela Confederação Nacional da Agricultura (CNA), com a liderança da Ministra Tereza Cristina (DEM/MS) e um discurso de que a agricultura empresarial e a familiar "são o mesmo negócio"; iii) o setor mais atrasado da renda fundiária, representado pela União Democrática Ruralista (UDR), que voltou a ter relevância no cenário político (a partir do processo eleitoral, articulando espaços regionais em apoio a Bolsonaro), com a nomeação de Nabhan Garcia Júnior para a Secretaria Especial de Assuntos Fundiários do Mapa e, iv) o setor vinculado ao militares, representado pelo general da reserva João Carlos Jesus Corrêa, que foi nomeado como Presidente do Incra, e sua equipe de coronéis que controlaram o Incra de fevereiro a outubro de 2019 (LEITE, TUBINO e SAUER, 2019). Em termos de agenda agrária e políticas para o campo, os primeiro e quarto grupos já não estão na disputa, ao menos não em 2020 e publicamente. O capital financeiro se impôs efetivamente, controlando ou dando rumos a parte significativa das políticas e incentivos ao agronegócio exportador. Os militares, o quarto grupo, não foi derrotado nessa disputa interna, mas deslocado para outras agendas e postos (VALENTE, 2020), inclusive galgando mais poder no governo (ARAUJO, 2020; CAVALCANTI, 2020) (SAUER, LEITE E TUBINO, 2020, p. 295).
} 
reavivam, os conflitos e a violência. O relatório de Conflitos no Campo de 2019, divulgado pela Comissão Pastoral da Terra, apontou que 102 camponesas, indígenas, quilombolas e lideranças foram vitimadas no campo. No total, foram 1.833 conflitos, $23 \%$ a mais do que em 2018 e a maior quantidade dos últimos 15 anos (CPT, 2019).

Se o cenário atual aponta um inegável recrudescimento do conflito e da violência, é preciso entender também que há uma trajetória histórica mais longa e permanente no repertório e na construção de tais conflitos e violências no Brasil. Conflito e violência seguem sendo a regra da dinâmica sociocultural, apontam para a latência de um conflito, que não se exaure apenas na noção de disputa por terras. Apesar da polissemia, a força do termo "conflito" remete à existência de classes e categorias que se estruturam em torno de antagonismos, lutas e identidades (CASTRO, 2019). Partindo dessa noção, o conflito se define como "[...] o estado de confronto entre forças opostas, relações sociais distintas, em condições políticas adversas [...]”, que buscam por meio da “[...] negociação, da manifestação, da luta popular, do diálogo, a superação, que acontece com a vitória, a derrota ou o empate [...]". Mais especificamente, o conflito por terra "[...] é um confronto entre classes sociais, entre modelos de desenvolvimento, por territórios, que pode ser 'esmagado' ou pode ser resolvido [...]" (FERNANDES, 2005, p.26).

O conflito ${ }^{5}$ por terras tem como um dos traços os processos de apropriação privada, iniciados pelo colonialismo, através daquilo que Souza Filho (2013) chamou de usurpação das terras e das gentes. A usurpação produziu a captura privada de grandes áreas, através de modelos agrários excludentes e concentradores, pautados pela destruição generalizada da natureza e das pessoas originárias (MARTINS, 1997; SOUZA FILHO e PRIOSTE, 2017). O pensamento eurocêntrico colocou a América Latina em estado de imaturidade total, incluindo a questão física das terras, vegetais e animais como primitivos, brutais e débeis (DUSSEL, 1994).

É fundamental colocar essa dinâmica socioeconômica em perspectiva histórica, pois a apropriação de terras vem ocorrendo há séculos, incluindo novas lógicas de expulsão (SASSEN, 2010; 2016), expropriações violentas (FAJARDO, 2009) e de "accumulation by dispossession" (HARVEY, 2003), expressão traduzida neste trabalho como acumulação por

\footnotetext{
${ }^{5} \mathrm{O}$ enfrentamento é um momento do conflito (FERNANDES, 2005; CASTRO, 2019). Mais que uma mera disputa, o conflito é marcado pela violência, podendo chegar à aniquilação de uma das partes. A apropriação privada de terras, por diversos meios como a compra e venda sob coação, expulsões, grilagem, fraudes, invasões e aplicação arbitrária de leis agrárias gera conflitos - dualismos e divergências (SIMMEL, 1983; 2011) - que desalojam, deslegitimam e negam identidades. Portanto, existem identidades sendo constantemente conformadas e ressignificadas em meio a conflitos, pelos quais o antagonismo das lutas e das resistências reavivam contraposições, usos, símbolos, projetos e demandas (CASTRO, 2019).
} 
despossessão, que se inserem em ciclos de acumulação de capital. Deve ser compreendida não apenas do ponto de vista físico, pela apropriação e posse diretas, mas também por formas menos visíveis de controle, como contratos agrários e arranjos empresariais. Subjacente a tais direitos e à sua construção, subsistem formas de valoração, aproveitamento, uso e acesso às terras.

A violência e a dominação política sobre terras e povos da América Latina remontam às práticas, legislações e outras formas de imposição do Estado e de grupos privados hegemônicos, originadas no período colonial. No colonialismo, o Estado promove, organiza ou coordena a colonização, mesmo que não tenha controle total sobre os colonos e que existam formas de colonização espontâneas que se realizam de forma mais ou menos autônoma (FERREIRA, 2014 et al, p. 275).

Nas relações coloniais, o Estado não é uma unidade abstrata ou isenta, separada do sistema de relações mundiais que se configuraram a partir de 1492. Segundo Castro-Gómez (2005), o Estado exerce uma função no interior desse sistema internacional de poder. Estado e grupos privados (grandes comerciantes e proprietários de terras) se inserem dentro da “despossessão colonial”, legitimada por um imaginário que estabelece identidades opostas e diferenças entre colonizador e colonizado. O colonizado aparece assim como o "outro da razão", o que justifica o exercício de um poder disciplinar por parte do colo-nizador (CASTRO-GÓMEZ, 2005, p. 173).

A maldade, barbárie e incontinência são marcas identitárias do colonizado, enquanto bondade, civilização e racionalidade seriam próprias do colonizador. Ambos se inserem "em relação de exterioridade e se excluem mutuamente". Uma política “justa” será aquela que, "mediante a implementação de mecanismos jurídicos e disciplinares, tente civilizar o colonizado através de sua completa ocidentalização" (CASTRO-GÓMEZ, 2005, p. 174).

Nessa linha, sociedades como a brasileira se formam diferentemente, mas sob um mesmo marco colonial de confronto entre forças opostas, de relações sociais distintas e de condições políticas adversas no interior do projeto colonial. A sociedade colonial é originariamente formada sob condições de antagonismo e exclusão, sob interesses e sujeitos distintos, que tornam importante questionar porque um saber se constitui e outro não. $O$ social, como circuito simbólico e material, funciona "a partir de centros em relação às margens", existindo segmentos que ficam "do lado de fora em relação ao centro", pois são "porta-vozes de demandas divergentes àquelas representadas politicamente, constituindo, com 
sua ação, um movimento de oposição e manifestação de conflitos” (HERNANDEZ, 2018, p. $54)$.

Embora seja diverso no tempo e no espaço (por exemplo, o colonialismo português e espanhol do século XVI difere do britânico do século XIX), trata-se de uma política de Estado. Foi voltada a conquistar e subjugar terras e povos (DUSSEL, 1994). Em última análise, legitimou a expropriação de recursos na América Latina.

\section{COLONIALISMO E APROPRIAÇÃO PRIVADA DE RECURSOS NATURAIS: IMPORTÂNCIA DO SESMARIALISMO E LEI DE TERRAS (1850).}

Existem confluências históricas entre o passado colonial ${ }^{6}$ e o acesso às terras, que se sucederam de políticas de conquista e dominação. O chamado colonialismo formal (BOBBIO et al, 1998) define as práticas institucionais e políticas de terras. É o processo de expansão, conquista e submissão de regiões habitadas por povos diferentes (colônias) da potência colonial (metrópoles). Define, mais propriamente, “[...] a organização de sistemas de dominação institucionalizada de um Estado" sobre povos e terras (BOBBIO et al, 1998, p. 181).

As colônias do século XVI, caso do Brasil, estavam inseridas em um sistema "mercantilista capitalista" o que, segundo Stavenhagen (2010), diz muito sobre a estreita relação entre colonialismo e capitalismo. Cabia à colônia complementar a economia metropolitana, modelo que atendia a política econômica de diversas nações, inseridas no capitalismo comercial dos séculos XVI e XVII, conhecido como mercantilismo. Nesse período, intensificaram-se a produção e concentração de riquezas, bem como o poderio estatal das metrópoles europeias e seus grupos privados comerciais (HUNT e SHERMAN, 2000).

Às relações econômicas do sistema "mercantil capitalista" (STAVENHAGEN, 2010) se somaram fatores de outra natureza, como o eurocentrismo (QUIJANO, 2002). O eurocentrismo é uma construção de conhecimentos, uma chave de leitura do século XX que lê/interpreta a colonização como "processo de eurocentralização do padrão de poder colonial/moderno/capitalista" (QUIJANO, 2005, p. 11). Em outros termos, expressa

\footnotetext{
${ }^{6}$ A partir de 1492, a Europa iniciou a submissão da América à economia colonial, em que as colônias não eram mais que abastecedoras de matérias-primas que alimentavam direta ou indiretamente diversos mercados (DUSSEL, 1994). As economias "extrovertidas" eram voltadas à exportação de recursos naturais (BOBBIO, 1998 et al, p. 185 e 186). Assim, o "motor da economia americana era o sistema mercantilis ta capitalista em expansão" (STAVENHAGEN, 2010, p. 149 e 150), que submetia o aproveitamento das terras, sua organização política e jurídica, a propósitos comerciais externos (da metrópole). Para Mignolo (2017, p. 02/03), até o século XVI, o mundo fora mais policêntrico que "capitalista", pois diversas civilizações ainda eram coexistentes, algumas com longas histórias, outras sendo formadas naquela época.
} 
legitimação das experiências de colonialismo e das necessidades do capitalismo. Permitiu impor o modo europeu de produção de conhecimento e de justificação da expropriação de terras "como a única racionalidade legítima, como a racionalidade hegemônica". Entre seus elementos principais está a "propensão reducionista e homogeneizante" de definir e identificar as experiências sociais na terra. Nesse contexto, o colonialismo na América foi condição essencial para consolidação do capitalismo no sistema global, com especificidades de "um padrão de poder de vocação mundial" (QUIJANO, 2005, p. 11).7

No Brasil, a propriedade sobre as terras surge como privilégio concedido pelo Rei de Portugal a grupos restritos, privados e ligados ao poder político. A concentração de terras adquire desde então o traço determinante de exclusão de direitos, destacando-se o ponto de partida na implantação do sesmarialismo (1530-1824) e, após a independência (1822), o aprofundamento trazido pela Lei $\mathrm{n}^{\circ} 601$, de 18 de setembro de 1850 , ou simplesmente, a "Lei de Terras", (CASTRO, 2019).

O sesmarialismo aplicado ao Brasil, do ponto de vista legal e de sua essência, não era uma cópia fiel do sesmarialismo português. Neste, havia uma preocupação maior com a utilização produtiva da terra, expressa na cláusula de condicionalidade da doação, atrelada ao cultivo (fixação de um prazo de três a cinco anos para a ocupação produtiva, findo o qual devia retornar à coroa portuguesa, caso a exigência não fosse cumprida). Vem daí o sentido original das terras devolutas, como aquelas concedidas e não-aproveitadas, que deveriam ser devolvidas ao doador, ou seja, à Coroa portuguesa. O termo, entretanto, passou ao vocabulário jurídico brasileiro "como sinônimo de terra vaga, não-apropriada, patrimônio público" e até o termo "sesmeiro" teve o seu significado original modificado, "pois em Portugal designava a autoridade que concedia a sesmaria e na colônia passou, pouco a pouco, a indicar o beneficiário da concessão" (SILVA e SECRETO, 1999, p. 114). No Brasil, sesmarias eram obtidas por concessão administrativa do domínio e não por transferência de propriedade.

\footnotetext{
7 A América constitui-se como o primeiro espaço/tempo de um padrão de poder de vocação mundial e, desse modo e por isso, como a primeira id-entidade da mo-dernidade. Dois processos históricos convergiram e se associaram na produção do referido espaço/tempo e estabeleceram-se como os dois eixos fundamentais do novo padrão de poder. Por um lado, a codificação das diferenças entre conquistadores e conquistados na ideia de raça, ou seja, uma supostamente distinta estrutura biológica que situava a uns em situação natural de inferioridade em relação a outros. Essa ideia foi assumida pelos conquistadores como o principal elemento constitutivo, fundacional, das relações de dominação que a conquista exigia. Nessas bases, consequentemente, foi classificada a população da América, e mais tarde do mundo, nesse novo padrão de poder. Por outro lado, a articulação de todas as formas históricas de controle do trabalho, de seus recursos e de seus produtos, em torno do capital e do mercado mundial (QUIJANO, 2005, p. 11)

${ }^{8}$ O Estatuto da Terra, de 30 de novembro de 1964, substituiu a Lei de Terras, de 1850, delimitando o módulo rural e a função social da propriedade (MAIA e LINHARES, 2016). Para Martins (1999), o Estatuto pode ser considerado a primeira de várias reformas da propriedade fundiária e da distribuição da terra agrária. Depois, o tema encontrou novamente espaço para uma ampla discussão na Assembleia Nacional Constituinte (ANC), instalada em 1\%/02/1987 até a promulgação constitucional em 05/10/1988. Na ANC foi possível visualizar "um conjunto de pontas desatadas desse longo e inacabado processo histórico" (MARTINS, 1999, p. 101).
} 
Entre o fim do regime sesmarial e a instituição da Lei de Terras, houve o período de quase 30 anos, chamado de "império de posses" ou "fase áurea do posseiro". Sem normatização e regulamentação, a posse tornou-se a única forma de aquisição de terras. Aumentou paulatinamente o número de posseiros, de grandes propriedades e também a ação de oligarquias rurais no Brasil (MAIA e LINHARES, 2016, p. 121). Após 1850, deu-se o marco legal de legitimação da grande propriedade privada de terras e, tecnicamente, de conceituação de terras devolutas e privadas no país.

A crise da escravidão, durante o século XIX, fez a discussão sobre a estrutura agrária girar em torno da abundância de terras e escassez de trabalhadores. Ou, ainda, na ideia de que, sem o escravo, "a terra tinha que ser cativa" (MARTINS, 1986, p. 32). Na prática, a ameaça à acumulação capitalista (como exemplo, o aumento de salários para a permanência dos trabalhadores) só poderia ser contornada com um projeto político que barrasse o acesso às terras livres, tornando-as propriedade privada, por meio da Lei de Terras de 1850 e de fomento à imigração de excedente populacional europeu pelo "Colonato". Segundo Silva (1996, p. 154), a Lei de Terras criou o instituto das "terras devolutas". Tecnicamente, Souza Filho (2003) as define como "uma espécie de direito originário próprio, que veio reconhecer como propriedade todas as sesmarias confirmadas pela produção, bem como a legitimação das posses" ocorridas entre 1822 e 1850 (SOUZA FILHO, 2003, p. 184). O conceito legal foi delimitado no artigo $3^{\circ}$ da Lei 601, de 18 de setembro de 1850.

Ponto central da Lei de Terras foi a consolidação de um regime de propriedade que impediu o acesso àqueles que não pudessem comprá-la (CASTRO, 2019). Isso a transformou definitivamente em mercadoria, inserida em um mercado, passível de negociação e registro formais. A propriedade da terra, "ao invés de ser atenuada para viabilizar o livre fluxo e reprodução do capital, [foi] enrijecida para viabilizar a sujeição do trabalhador livre ao capital proprietário de terra" (MARTINS, 1997, p. 12). Na prática, as nações indígenas, os negros recém libertos (ex-escravos), camponeses e imigrantes pobres ficaram impedidos de acessar legalmente terras, senão pela compra, o que se daria com dificuldades óbvias, pois os preços eram frequentemente superiores às possibilidades econômicas (OLIVEIRA, 2001). A Lei de Terras, de 1850, também teve papel fundamental para a transição do trabalho escravo ao livre (colonato), abrindo a possibilidade de "transformar a terra em renda territorial capitalista, permitindo ao fazendeiro transfigurar seu capital, anteriormente investido em escravos, na aquisição de terras". Estabeleciam-se condições para manter o padrão de acumulação, sem 
prejuízo aos interesses dos grandes proprietários, como os fazendeiros de café do século XIX e XX (MARTINS, 1986, p. 32).

A partir de então, qualquer propriedade privada sobre terras no Brasil deveria ser originada por uma concessão sesmarial anterior e validada, ou comprada de outro proprietário, formando-se uma cadeia sucessória e cartorial de proprietários. O processo de validação das terras e de confirmação do regime público ou privado foi regulamentada pelo Decreto $\mathrm{n}^{\circ}$. 1.318, de 30 de janeiro de 1854.

Se, por um lado, a constituição da força de trabalho escravo e, depois assalariado foi regulada "antes de mais nada, pelas regras de comércio" (MARTINS, 2000, p. 30), essa lógica continuou se desdobrando, nos marcos de restrição a direitos e cidadania, pela inserção da terra no mercado (SOUZA FILHO, 2003; SAUER, 2010), isto é, da transformação da terra em coisa e "mercadoria" passível de negociação, a partir de 1850.

Embora o capital existisse antes da conquista da América (MIGNOLO, 2017), foi com a colonização que ele pôde consolidar-se, tornando-se o eixo em torno do qual todas as demais formas de expropriação foram articuladas para os fins do mercado mundial. Assim, o colonialismo antecede o capitalismo enquanto sistema mundial e o acompanha como política em suas diferentes fases de desenvolvimento (FERREIRA et al, 2014). A expansão europeia do século XVI teve o colonialismo como seu componente central e a acumulação primitiva ${ }^{9}$ tornou o capitalismo possível como "modo de produção" (FERREIRA et al, 2014, p. 255).

\section{COLONIALISMO E CAPITALISMO: BREVES MARCOS CONCEITUAIS}

A expropriação dos pequenos produtores através dos cercamentos ("enclousures") dos campos europeus teria sido, segundo Velho (2009), o principal mecanismo interno da acumulação primitiva e que não teria se dado isoladamente. Ela se combinou com a expropriação de terras nas colônias, por elementos como a expulsão de povos originários, a extração comercial de recursos naturais, o tráfico de escravos, etc. (VELHO, 2009, p. 41),

\footnotetext{
9 A acumulação primitiva é um processo histórico localizado no início do modo de produção capitalista, abrangendo as condições para a formação histórica do capital e sua extensão para outros espaços e modos de produção (READ, 2003). Novas pessoas e recursos foram e continuam sendo incorporados às relações sociais capitalistas (HALL, 2013). Portanto, "a acumulação primitiva não se restringiria ao momento em que, ou ao local em que a produção capitalista surgiu", não sendo determinado se o conceito deveria ser restrito a esse passado (BIN, 2018, p. 78). Para Levien (2014, p. 25), a acumulação primitiva representa aqueles processos históricos que inauguram as relações sociais capitalistas, gerando "precondições" antes de o capitalismo recriar internamente "suas próprias condições". O capitalismo foi capaz de estender "as relações coloniais sobre o espaço e as formas sociais", atualizando-o como "componente estrutural de seu próprio sistema e amplificando de forma nunca antes vista sua dimensão e significado" (FERREIRA, 2014 et al, p. 254). A acumulação primitiva oc orreu na Europa (OLIVEIRA, 1991; MARTINS, 1994; VELHO, 2009), mas se manifestou por mecanismos internos e externos que atingiram as terras e povos na América.
} 
confluindo naquilo que Marx (2000, p. 875) considerava ser "isolar o produtor dos meios de produção".

No entanto, podemos interpretar a teoria da acumulação primitiva de Marx também como distinção específica entre os processos (não capitalistas) que possibilitam a emergência de um modo de produção capitalista, no qual "conquista, escravização, roubo, assassinato, ou seja, violência exerceu o maior papel" [...], e um sistema capitalista maduro que, uma vez desenvolvido, dispensa a coerção extra-econômica e confia na "compulsão silenciosa das relações econômicas" [...]. Na primeira definição, é a função que distingue a acumulação primitiva da acumulação capitalista - ela gera as precondições do capitalismo antes de o capitalismo assumir o poder e recriar internamente suas próprias condições. Na segunda definição, são os meios extraeconômicos da acumulação primitiva que a separam da acumulação capitalista propriamente dita (LEVIEN, 2015, p. 26).

Portanto, a acumulação primitiva envolveu a expropriação, sob uma série de lutas episódicas e violentas na Europa (HUNT e SHERMAN, 2000). Na interpretação de Harvey (2003) e Levien (2014), a acumulação primitiva foi a aurora da era capitalista e, ao mesmo tempo, um de seus aspectos "contínuos e constitutivos" (LEVIEN, 2014, p. 45). A acumulação primitiva não seria, segundo Levien $(2014 ; 2015)$, adequada para explicar a persistência de estratégias predatórias no capitalismo contemporâneo. Os processos de acumulação teriam aspectos contínuos no capitalismo atual, levando a sistemas mais complexos de despossessão. ${ }^{10}$

Os textos originais de Levien (2014) e Harvey (2003) foram traduzidos no Brasil com algumas dissonâncias e polissemias, particularmente quanto a termos como expropriação, desapropriação, espoliação e despossessão. Na crítica de Bin (2018), as despossessões contemporâneas foram relacionadas com a acumulação capitalista, sem cuidados teóricos suficientes para distinguí-las.

Para alguns juristas (MEIRELLES, 2014), a diferença entre expropriação e desapropriação está na motivação e na indenização. Na desapropriação ocorre a perda da propriedade privada, por um ato do Poder Público que retira e indeniza. Não é uma medida confiscatória. Já a expropriação, no sentido jurídico, é o ato estatal unilateral que produz a

\footnotetext{
${ }^{10}$ A maneira como as sociedades expropriam terra e recursos naturais e a maneira como produzem espaço para qualquer configuração político-econômica são igual-mente centrais; na verdade, contêm um potencial político explosivo em muitas partes do Hemisfério Sul atual. Incentivados por uma proliferação de movimentos e levantes contra várias formas de expropriação e cercamento, os estudiosos es-tão agora se perguntando se a "acumulação primitiva", identificada por Marx com a aurora da era capitalista, não seria, na verdade, um de seus aspectos contínuos e constitutivos (LEVIEN, 2014, p. 45).
} 
extinção da propriedade sem qualquer tipo de indenização, como punição a ato ilícito. Por exemplo, atualmente no Brasil e na Colômbia as terras com cultivos ilícitos podem ser expropriadas e não desapropriadas, pois há um caráter sancionatório na perda imposta pelo Estado (DI PIETRO, 2013).

Partindo da carga jurídica (de "retirada e perda"), mas além dela, interessa destacar neste trabalho que o sentido está contextualizado na ideia de apropriação capitalista da terra (FERNANDES, 2005; OLIVEIRA, 2007; MARTINS, 2009). Envolve meios lícitos e ilícitos, como também mecanismos violentos, excludentes e concentradores que podem resultar na expulsão dos sujeitos coletivos (SASSEN, 2010; 2016). A expulsão - no conceito de Sassen (2016) - é a completa negação de direitos, inclusive sobre a terra. Não é somente a violência pelo seu início de apropriação violenta, mas a consequência, a negação do próprio direito de ser camponês.

Para Harvey (2003), diversos mecanismos de apropriação podem ser compreendidos na lógica da "acumulation by dispossession" ou acumulação por despossessão, tam-bém traduzida como acumulação por espoliação. Segundo ele, "a acumulação primitiva que abre caminho à reprodução expandida é bem diferente da acumulação por desposses-são, que faz ruir e destrói um caminho já aberto" (HARVEY, 2003, p. 135). Em vez de produzir riqueza, apropria-se da riqueza já existente, ainda que isso termine por derruir ainda mais as bases de funcionamento da economia. Altvater (2010) entende que na acumulação por despossessão “andam de mãos dadas a privatização de bens e serviços públicos, manobras corruptas e criminosas, o acesso político e militar aos recursos naturais, sobretudo ao petróleo, o roubo de obras do patrimônio artístico e sua transformação em antiguidades comercializadas", bem como "o interesse especulativo e a retirada de direitos sociais e democráticos de cogestão" (ALTVATER, 2010, p. 112).

A acumulação primitiva é uma "construção histórica" porque ocorreu no início do modo de produção capitalista. E é uma "construção teórica", porque a própria lógica da acumulação capitalista pressupõe a existência das condições sociais mencionadas para que ela ocorra (BIN, 2018, p. 78). O conceito de acumulação primitiva só pode ser entendido em relação ao conceito de acumulação capitalista . Mais especificamente, a compreensão da acumulação primitiva requer uma compreensão prévia de mercadoria, pois esta é o ponto de partida do modo de produção capitalista propriamente dito (BIN, 2018). 
Nos níveis histórico e conceitual, o foco central da exposição sobre a acumulação primitiva é mostrar o movimento do qual surgiram os fundamentos do modo de produção capitalista. No debate sobre a acumulação primitiva supostamente em andamento, esta não pode ser equiparada à acumulação primitiva (clássica). Segundo Bin (2018, p. 78), o principal problema é que na acumulação por despossessão "ignora-se a necessidade da transformação de produtores diretos em proletários para que a acumulação real ocorra", diferentemente da acumulação primitiva clássica, em que as despossessões não trazem, por si só, trabalho proletário adicional à economia, que é uma condição para a expansão do capital.

Por outro lado, o caráter permanente da acumulação primitiva está presente em uma série de diferentes trabalhos (PERELMAN, 2000; DE ANGELIS, 2001; 2007; ARRIGHI, 2007; 2010; SASSEN, 2010; 2013; LEVIEN, 2014) nos quais, sob diferentes roupagens, os mecanismos violentos de expulsão e apropriação privada de terras e recursos naturais compõem a acumulação por despossessão. Na prática, ativos públicos e comuns foram cerceados, permitindo o uso privado, excludente e lucrativo dos recursos.

Para Harvey (2003), são diversas as formas de despossessão contemporâneas, "que se colocam distintas e geograficamente dispersas, cuja significância para o capital residiria muito mais no ativo expropriado que na força de trabalho das pessoas" (HARVEY, 2003, p. 36). A acumulação por despossessão seria ilustrada com base em quatro elementos principais: a) privatização, que é a transferência de ativos dos domínios públicos para os domínios privados governados pelo capital; b) financeirização, estimulada pela desregulamentação do sistema financeiro e tornou-se uma das principais formas de redistribuição de superávits por meio de especulação, predação, fraude e roubo; c) gestão e manipulação de crises no cenário mundial, o que levou a processos deliberados de redistribuição de riqueza de países pobres para países ricos; e d) redistribuições estatais, que envolvem reformas fiscais e tributárias destinadas a reduzir o salário social e favorecer o retorno do investimento corporativo (HARVEY, 2003; BIN 2018).

Como a privatização e a liberalização do mercado foram o mantra do movimento neoliberal, o resultado foi transformar em objetivo das políticas do Estado a 'expropriação das terras comuns'. Ativos de propriedade do Estado ou destinados ao uso partilhado da população e geral foram entregues ao mercado para que o capital sobreacumulado pudesse investir neles, valorizá-los e especular com eles (HARVEY, 2003, p. 130/131). 
Tomando os elementos acima (HARVEY, 2003), alterações substanciais aconteceram principalmente após os anos 1970, com projetos, concessões, aquisições e arrendamento de terras para corporações privadas. Isso expõe situações nas quais o controle por terras e recursos naturais, “[...] que pode ou não envolver a apropriação e a administração concreta de territórios [...]”, passou a ser um meio necessário para a acumulação de capital. Desnudou-se uma "acumulação por despossessão" que consiste numa recorrente, persistente e predatória prática de "acumulação primitiva", que Harvey (2003) considera de caráter permanente. O conceito aborda o processo de expansão de limites espaciais, políticos e socioeconômicos da acumulação de capital, “[...] permitindo expor a tensão entre as formas de provisão coletiva e a acumulação capitalista”. A acumulação primitiva do passado persiste como "acumulação por despossessão" e leva a novas batalhas políticas e re-sistência sociais (HARVEY, 2003, p. 134).

Entre o passado da acumulação primitiva (MARX, 2000) e seus aspectos contínuos e presentes na acumulação por despossessão (HARVEY, 2003), o espaço-tempo do colonialismo se manifestou por processos históricos inter-relacionados - tais como o capitalismo (enquanto arquétipo de exploração social), o Estado (como plataforma de controle de coletividades e territórios), a colonialidade do poder (que erigiu a noção de "raça" para o padrão de classificação e dominação social) e o eurocentrismo (forma hegemônica de controle da subjetividade e da intersubjetividade, em particular no modo de produzir conhecimento) (QUIJANO, 2000; 2002; 2005). Em tal cenário, a apropriação da terra e distribuição de produtos foram articuladas em torno do mercado mundial. ${ }^{11}$

A produção de metais preciosos nos séculos XV a XVII, mas sobretudo no XVIII (coincidindo a descoberta do ouro brasileiro e o auge manufatureiro inglês) levaram, no século XIX, a uma forte articulação entre a expropriação de terras e metais na América e as demandas da economia mundial (MARINI, 2000). Embora o modo capitalista de produção se desenvolvesse plenamente no século XIX, as relações sociais na América Latina

\footnotetext{
11 [...] todas as formas de controle e de exploração do trabalho e de controle da produção-apropriação-distribuição de produtos foram articuladas em torno da relação capital-salário (de agora em diante capital) e do mercado mundial. Incluíram-se a escravidão, a servidão, a pequena produção mercantil, a reciprocidade e o salário. Em tal contexto, cada umas dessas formas de controle do trabalho não era uma mera extensão de seus antecedentes históricos. Todas eram histórica e sociologicamente novas. Em primeiro lugar, porque foram deliberadamente estabelecidas e organizadas para produzir mercadorias para o mercado mundial. Em segundo lugar, porque não existiam apenas de maneira simultânea no mesmo espaço/tempo, mas todas e cada uma articulada com o capital e com seu mercado, e por esse meio entre si. Configuraram assim um novo padrão global de controle do trabalho, por sua vez um novo elemento fundamental de um novo padrão de poder, do qual eram conjunta e individualmente dependentes histórico-estruturalmente. Isto é, não apenas por seu lugar e função como partes subordinadas de uma totalidade, mas também porque sem perder suas respectivas características e sem prejuízo das descontinuidades de suas relações com a ordem conjunta e consigo mesmas, seu movimento histórico dependia desse momento em diante de seu pertencimento ao padrão global de poder. Em terceiro lugar, e como conseqüência, para preencher as novas funções cada uma delas desenvolveu novos traços e novas configurações histórico-estruturais (QUIJANO, 2005, p. 229).
} 
“assentavam-se, por exemplo, no trabalho escravo, com marcas de um capitalismo altamente contraditório e dependente" (FERREIRA e TORRES, 2016, p. 04). O capital se manifestou como "o eixo dominante da articulação conjunta de todas as formas historicamente conhecidas de controle e exploração do trabalho, configurando assim um único padrão de poder, histórico-estruturalmente heterogêneo, com relações descontínuas e conflitivas entre seus componentes" (QUIJANO, 2000, p. 248).

Portanto, a América Latina não foi, e nem é, um espelho do capitalismo central, ocorrido na Europa ou, posteriormente, nos Estados Unidos. O ingresso das nações latinoamericanas no sistema capitalista em escala mundial determinou “[...] seu processo de formação econômico-social, à medida que o estatuto colonial, ao impulsionar o movimento metropolitano à acumulação capitalista, freou o desenvolvimento nas áreas coloniais" (PAIVA, ROCHA e CARRARO, 2010, p. 152). Para pensadores como Mariátegui (1999), os países latino-americanos chegariam sempre "atrasados à concorrência capitalista", pois "os primeiros lugares já foram definitivamente atribuídos. O destino desses países, na ordem capitalista, é o de simples colônias" (MARIÁTEGUI, 1999, p. 112).

Como parte deste processo mais amplo, no século XIX, as colônias espanholas e portuguesas da América ascenderam ao status de países independentes. Tiveram nas mãos “o destino do imenso patrimônio de terras que o primeiro ciclo de colonização colocara sob o domínio das metrópoles européias, à custa, na maioria das vezes, das populações indígenas locais" (SILVA e SECRETO, 1999, p. 109) ${ }^{12}$.

Partindo dessas lógicas, se produziram os mecanismos de apropriação privada das terras da América Latina. De um lado, com políticas de dominação e expropriação sobre povos pertencentes a civilizações diversas e longínquas (BOBBIO et al, 1998). De outro, os mecanismos se efetivaram não apenas pelo Estado, mas "por meio de uma série de empresas mercantis pelas quais interviam grandes capitais privados e participação estatal" (STAVENHAGEN, 2010, p. 148). As relações sociais, econômicas e políticas decorrentes subsistiram em diferentes graus e feições de hierarquias sociais. ${ }^{13}$

\footnotetext{
${ }^{12} \mathrm{O}$ corte dos vínculos coloniais desencadeou importantes conseqüências na vida econômica na medida em que propiciou “ [...] o surgimento de novos padrões de organização interna do fluxo de renda". Internalizado, o fluxo de renda aumentou "a diferenciação dos papéis econômicos (senhoriato rural, grandes comerciantes de importação e exportação) e a circulação de capitais", facilitando a inserção desses países na nova ordem econômica mundial (SILVA e SECRETO, 1999, p. 110).

${ }_{13}$ As hierarquias sociais são um exemplo de continuidades das relações coloniais em um mundo pós-colonial (QUIJANO, 2005). Um exemplo de hierarquia social que determinava relações de exclusão sobre a terra, é a noção de raça e identidade racial. Elas "foram estabelecidas como instrumentos de classificação social básica da população". A ideia de raça "foi uma maneira de outorgar legitimidade às relações de dominação impostas pela conquista". A Europa como "nova identidade depois da América e a expansão do colonialismo europeu ao resto do mundo conduziram à elaboração da perspectiva eurocêntrica do conhecimento e com ela à elaboração teórica da ideia de raça" como naturalização das relações coloniais de dominação “entre europeus e não-europeus” (QUIJANO, 2005, p. 229).
} 


\section{NOTAS PARA UMA CONCLUSÃO}

Entre o passado da acumulação primitiva (MARX, 2000) e seus aspectos contínuos e presentes na acumulação por despossessão (HARVEY, 2003), o espaço-tempo do colonialismo se manifestou por processos históricos inter-relacionados, tais como o capitalismo (enquanto arquétipo de exploração social), o Estado (como plataforma de controle de coletividades e territórios), a colonialidade do poder (que erigiu a noção de "raça" para o padrão de classificação e dominação social) e o eurocentrismo (forma hegemônica de controle da subjetividade e da intersubjetividade, em particular no modo de produzir conhecimento). Embora o capital existisse antes da conquista da América, foi com a colonização que ele pôde consolidar-se. Assim, o colonialismo antecede o capitalismo enquanto sistema mundial e o acompanha como política em suas diferentes fases de desenvolvimento.

A expansão europeia do século XVI teve o colonialismo como seu componente central e a acumulação primitiva tornou o capitalismo possível como "modo de produção". A acumulação primitiva é um processo histórico localizado no início do modo de produção capitalista, abrangendo as condições para a formação histórica do capital e sua extensão para outros espaços e modos de produção. Partindo dessas lógicas, se produziram os mecanismos de apropriação privada das terras da América Latina. De um lado, com políticas de dominação e expropriação sobre povos pertencentes a civilizações diversas. De outro, os mecanismos se efetivaram não apenas pelo Estado, mas por meio de uma série de empresas, grandes capitais privados e participação estatal. As relações sociais, econômicas e políticas decorrentes subsistiram em diferentes graus e feições de hierarquias sociais, que são um exemplo de continuidades das relações coloniais em um mundo pós-colonial. O colonialismo legitimou a expropriação e concentração de riquezas, ao mesmo tempo em que viabilizou a posse de grandes áreas de terra e de grandes quantidades de capital.

Em tal cenário, a apropriação da terra e distribuição de produtos foram articuladas em torno do mercado mundial. No pensamento de Harvey (2003), a acumulação por despossessão pode ser ilustrada com base em quatro elementos principais: privatização, financeirização, gestão e manipulação de crises no cenário mundial e as redistribuições estatais, que envolvem reformas fiscais e tributárias destinadas a reduzir o salário social e favorecer o retorno do investimento corporativo.

\section{REFERÊNCIAS}


ALTVATER, Elmar. O fim do capitalismo como o conhecemos. Rio de Janeiro: Civilização Brasileira, 2010.

ARRIGHI, Giovanni. Adam Smith in Beijing: Lineages of the twenty-first century. Londres: Verso. 2007.

ARRIGHI, Giovanni; ASCHOFF, Nicole e SCULLY, Ben. Accumulation by dispossession and its limits: The Southern Africa paradigm revisited. Studies in Comparative International Development, 45, p. 410-438. 2010.

BARBOSA, Catarina. Plataforma emergencial propõe medidas de defesa do campo, das florestas e das águas. Brasil de Fato. Belém (PA). 13 de Maio de 2020. Disponível em: https://www.brasildefato.com.br/2020/05/13/plataforma-emergencial-propoe-medidas-dedefesa-do-campo-das-florestas-e-das-aguas. Acesso em 08.nov.2020.

BERNARDES, José Eduardo. Indígenas, quilombolas e camponeses denunciam aumento de ataques durante a pandemia. Brasil de Fato. São Paulo (SP). 15 de Maio de 2020. Disponível em: https://www.brasildefato.com.br/2020/05/15/indigenas-quilombolas-ecamponeses-denunciam-aumento-de-ataques-durante-a-pandemia. Acesso em 08.nov.2020.

BIN, Daniel. So-called Accumulation by Dispossession. Critical Sociology, v. 44, p. 75-88, 2018.

BOBBIO, Norberto; MATTEUCCI, Nicola; PASQUINO, Gianfranco. Dicionário de política. Trad. Carmen C, Varriale et ai.; coord. trad. João Ferreira; rev. geral João Ferreira e Luis Guerreiro Pinto Cacais. Brasília : Editora Universidade de Brasília, 1 la ed., 1998.

CASTRO, Luís Felipe Perdigão. CONFLITOS POR TERRA NO BRASIL E NA COLÔMBIA: MECANISMOS DE APROPRIAÇÃO PRIVADA E OS CAMPONESES COMO SUJEITOS COLETIVOS DE DIREITO. Tese (Ciências Sociais). Universidade de Brasília, Brasília, 2019.

CASTRO-GÓMEZ, Santiago. Ciências sociais, violência epistêmica e o problema da "invenção do outro". In: A colonialidade do saber: eurocentrismo e ciências sociais. Perspectivas latino-americanas. Edgardo Lander (org). Colección Sur Sur, CLACSO, Ciudad Autónoma de Buenos Aires, Argentina. Setembro, p.169-186, 2005.

CPT. Comissão Pastoral da Terra. Conflitos no Campo Brasil 2019. Centro de Documentação Dom Tomás Balduino, CPT. Goiânia/GO. 2019.

DE ANGELIS, Massimo. Marx and primitive accumulation: The continuous character of capital's enclosures. The Commoner, 2, p. 1-22. 2001.

The beginning of history: Value struggles and global capital. Londres: Pluto Press. 2007.

DI PIETRO, Maria Sylvia Zanella. Direito Administrativo. São Paulo, Atlas, 2013.

DUSSEL, Enrique. 1492: el encubrimiento del otro: hacia el origen del mito de la modernidad. La Paz: UMSA. Facultad de Humanidades y Ciencias de la Educación/Plural Editores: La Paz, 1994.

FAJARDO, Dario. Territorios de la agricultura colombiana. Universidad Externado de Colombia, Facultad de Ciencias Sociales y Humanas, edition 1, volume 1, number 56, 2009.

FERREIRA, Karolinne Krízia; TORRES, Maria Adriana. A formação do capitalismo na América Latina: peculiaridades das políticas sociais. Trabalho, crise e políticas sociais na América Latina. In: X Seminário do Trabalho, 2016, São Paulo, 2016.

FERNANDES, Bernardo Mançano. Contribuição ao estudo do campesinato brasileiro e formação e territorialização do Movimento dos Trabalhadores Rurais Sem Terra (1979 -1999). 1999, 318 f. Tese. Doutorado em Geografia. Faculdade de Filosofia, Letras e Ciências Humanas, Universidade de São Paulo, São Paulo, 1999. 
A ocupação como forma de acesso à terra. In: $8^{\circ}$ Encontro de Geógrafos da América Latina, 2001, Santiago de Chile. Anais do 8 Encontro de Geógafos da América Latina. Santiago de Chile: Universidad de Chile, v.1, 2001.

. Espaços agrários de inclusão e exclusão social: novas configurações do campo brasileiro. São Paulo: AGRÁRIA, n. 1, p. 16-36. 2004.

Questão agrária: conflitualidade e desenvolvimento territorial. In: BUAINAIN, A. M.

(Org.). Luta pela terra, reforma agrária e gestão de conflitos no Brasil. Campinas: Unicamp, 2005.

FERREIRA, Heline; NOGUEIRA, Caroline; SOUZA FILHO, Carlos Frederico Marés. Direito socioambiental: uma questão para a América Latina. 1. ed. Curitiba: Letra da Lei, v. 1.2014.

GROSFOGUEL, Ramon. The epistemic decolonial turn beyond political-economy paradigms. Cultural Studies, v. 21, n. 2-3, Mar./May 2007, p. 211-223, 2007.

. "Descolonizando los universalismos occidentales: el pluri-versalismo transmoderno decolonial desde Aime Cesaire hasta los zapatistas", em Castro-Gomez, Santiago \& Grosfoguel, Ramon (coords.) El giro decolonial: reflexiones para uma diversidad epistêmica más allá del capitalismo global. Bogota: Siglo del Hombre Editores, Instituto Pensar. 2008.

HEREDIA, Fernando Martinez. Nossa América e a águia temível. In: Adauto Novaes (org): Oito visões da América Latina. São Paulo: Ed. SENAC, 2006.

HERNANDEZ, Aline Reis Calvo. Ensaio sobre o poder: capilaridades, cadeiras-cativas e dissidências. In: Patrícia Binkowski. (Org.). Análise de conflitos e relações de poder em espaços rurais. 1ed.Porto Alegre: Editora da UFRGS, 2018, v. 1, p. 1-87.

HALL, Derek. Primitive accumulation, accumulation by dispossession and the global land grab. Third World Quarterly. V. 34, n. 9, p. 1582-1604. 2013.

HUNT, Emery K.; SHERMAN, Howard J. História do pensamento econômico. Petrópolis: Vozes, 2000.

LEITE, Acácio Zuninga; TUBINO, Nilton Luís Godoy; SAUER, Sérgio. Políticas públicas para terra e território: um olhar prospectivo sobre os próximos quatro anos no campo brasileiro. In: POCHMANN, Márcio; AZEVEDO, José Sergio Gabrielli de. Brasil: incertezas e submissão? São Paulo, Editora Perseu Abramo, 2019, p. 171-190.

LEVIEN, Michael. DA ACUMULAÇÃO PRIMITIVA AOS REGIMES DE DESAPROPRIAÇÃO. Tradução de Markus Hediger. Sociologia \& Antropologia. Vol.4, n.1, p.21-53, 2014.

. From Primitive Accumulation to Regimes of Dispossession: Six Theses on India's Land Question. Economic \& Political WEEKLY, v. 50, n. 22, 2015.

MAIA, Gretha Leite; LINHARES, Alaíde. A questão agrária brasileira na constituinte de 1987 em torno do conceito de propriedade. In: Encontros Universitários UFC 2016. Revista Encontros Universitários da UFC. Fortaleza: UFC, 2016. v. 1. p. 692-692. 2016.

MARIÁTEGUI, José Carlos. A revolução socialista latinoamericana. In: LOWY, Michael (org.) O marxismo na América Latina: uma antologia de 1909 aos dias atuais. São Paulo: Perseu Abramo. 1999.

MARINI, Ruy Mauro. Dialétia da Dependência. In: Dialética da Dependência: uma antologia da obra de Ruy Mauro Marini. Organização e apresentação de Emir Sader. Petrópolis, RJ: Vozes; Buenos Aires: CLACSO, 2000.

MARTINS, José de Souza. O poder do atraso: ensaios de sociologia da história lenta. São Paulo: Hucitec, 1994. 
A questão agrária brasileira e o papel do MST. In Stédile, J. P. (ed.) A reforma agrária e a luta do MST. Petrópolis: Vozes. 1997.

. Reforma agrária: o impossível diálogo sobre a História possível. Tempo Social. São Paulo, v. 11, n. 2, p. 97-128. 1999.

O cativeiro da terra. Hucitec, São Paulo, 1986 e 2000.

FRONTEIRA - A degradação do Outro nos confins do humano. 2. ed. SP: Contexto, v. 1. 190p. 2009.

MARX, Karl. Teorias da Mais-Valia: História Crítica do Pensamento Econômico, vol. II. São Paulo: DIFEL, 1983.

O Capital: crítica da economia política. Trad. Regis Barbosa e Flávio R. Kothe. São Paulo: Nova Cultural. Livri I, vol. 2, 1985.

O capital. São Paulo: Nova Cultural. 1986a.

Formações econômicas pré-capitalistas. Rio de Janeiro: Paz e Terra, 1986 b.

O capital. Volume I. São Paulo: DIFEL, 2000.

MEIRELLES, Hely Lopes. Direito administrativo brasileiro. São Paulo: Malheiros, 2014.

MELLO, Janine. Estratégias de superação da pobreza no Brasil e impactos no meio rural. Rio de Janeiro: Ipea, 2018.

MIGNOLO, Walter D. The darker side of western modernity: global futures, decolonial options. Durham, Duke University Press. 2011.

Colonialidade: o lado mais escuro da Modernidade. Tradução de Marco Oliveira (PUC-RJ). Revista Brasileira de Ciências Sociais, vol. 32, nº 94, p. 02-18, junho de 2017.

NORTH, Douglass C. Institutions, Institutional Change and Economic Performance. Cambridge University Press, New York. 1990.

OLIVEIRA, Ariovaldo Umbelino. Questões teóricas sobre a agricultura camponesa. In: OLIVEIRA, A. A agricultura camponesa no Brasil. São Paulo: Contexto. 1991.

A longa marcha do campesinato brasileiro: movimentos sociais, conflitos e Reforma Agrária. Estudos Avançados, São Paulo, v. 15, n. 43, p. 185-206, set/dez. 2001.

Modo Capitalista de Produção, Agricultura e Reforma Agrária. $1^{\text {a }}$. ed. São Paulo: FFLCU/LABUR EDIÇÕES, v. 1. 184p, 2007.

PAIVA, Beatriz; ROCHA, Mirella; CARRARO, Dilceane. Política Social na América Latina: ensaio de interpretação a partir da Teoria Marxista da Dependência. Brasília: SER Social, Jan. Jun.v.12.n.26.p.147-175. 2010.

PERELMAN, Michael. The invention of capitalism: Classical political economy and the secret history of primitive accumulation. Durham: Duke University Press. 2000.

QUIJANO, Aníbal. Colonialidade do poder, eurocentrismo e América Latina. In: Lander, Edgardo (Org.). A colonialidade do saber: eurocentrimos e ciências sociais. Perspectivas latino-americanas. Buenos Aires: Clacso, 2005.

Raza, etnia y nación en Mariátegui: cuestiones abiertas. In Roland Forgues (org.),

José Carlos Mariátegui y Europa: el otro aspecto del descubrimiento, Lima, Empresa Amauta. 1993.

Colonialidad del poder y clasificacion social. Journal of world-systems research, v. 11, n. 2. 2000.

. Colonialidade, Poder, Globalização e Democracia. Novos Rumos, ano 17, $n^{\circ}$ 37. São Paulo. 2002.

. Colonialidade do poder, eurocentrismo e América Latina. In: Lander, Edgardo

(Org.). A colonialidade do saber: eurocentrimos e ciências sociais. Perspectivas latinoamericanas. Buenos Aires: Clacso, 2005. 
Colonialidade do poder e classificação social. In Santos, Boaventura de Sousa; Meneses, Maria Paula (Organizadores). Epistemologias do Sul. São Paulo, Cortez, p. 84-126, 2010.

READ, Jason. The Micro-politics of Capital: Marx and the Prehistory of the Present. Albany, NY: State University of New York Press. 2003.

SASSEN, Saskia. A savage sorting of winners and losers: Contemporary versions of primitive accumulation. Globalizations, 7/1, p. 23-50. 2010.

. Land Grabs today: Feeding the disassembling of national territory. Globalizations. Vol. 10, no 1, p. 25-46, 2013.

Expulsões: brutalidade e complexidade na economia global. 1.ed. Rio de Janeiro: Paz e Terra. 2016.

SAUER, Sérgio. Terra e modernidade: a reinvenção do campo brasileiro. 1. ed. São Paulo: Expressão Popular, 2010.

SAUER, Sérgio; LEITE, Acácio Zuninga; TUBINO, Nilton Luiz Godoy. AGENDA POLÍTICA DA TERRA NO GOVERNO BOLSONARO. Revista da ANPEGE. v. 16. $\mathrm{n}^{\circ}$. 29, p. 283 - 316, 2020.

SILVA, Ligia Osorio; SECRETO, Maria V . Terras Públicas, ocupação privada: elementos para a história comparada da apropriação territorial na Argentina e no Brasil. Economia e Sociedade (UNICAMP), Campinas, SP, v. n.12, p. 109-141, 1999.

SILVA, Lígia Osório. A Lei da Terra - Um Estudo sobre a História da Propriedade da Terra no Brasil. Tese de Doutorado em Ciências Sociais. São Paulo: PUC-SP. 1990.

Terras devolutas e latifúndio: efeitos da Lei de 1850. Campinas: Ed. UNICAMP, 1996.

SIMMEL, Georg. A natureza sociológica do conflito. In: E. Morais (Org.). Simmel: sociologia. São Paulo: Editora Ática, 1983.

O conflito como sociação. Tradução de Mauro Guilherme Pinheiro Koury. RBSE -

Revista Brasileira de Sociologia da Emoção, v. 10, n. 30, p. 568-573. 2011.

SOUZA FILHO, Carlos Frederico Marés; PRIOSTE, Fernando. Quilombos no Brasil e direitos socioambientais na América Latina. REVISTA DIREITO E PRÁXIS, v. 8, p. 29032926, 2017.

SOUZA FILHO, Carlos Frederico Marés. Função social da terra. In: Homero Bezerra Ribeiro; Márcio Ferreira Rodrigues Pereira; Talita Furtado Montezuma; Thiago Arruda Queiroz Lima; et a. (Org.). Acesso à Terra e Direitos Humanos. 1ed.Fortaleza: Edições UFC, 2015, v. 1, p. 143-162. 2015.

142p. 2003.

A função social da terra. 1. ed. Porto Alegre: Sergio Antonio Fabris Editor, v. 1.

STAVENHAGEN, Rodolfo. Los pueblos originarios: el debate necesario. Fernández N. (comp.), CTA Ediciones, CLACSO, Buenos Aires, 2010.

VELHO, Otávio Guilherme. Capitalismo autoritário e campesinato: um estudo comparativo a partir da fronteira em movimento. Rio de Janeiro: Centro Edelstein de Pesquisas Sociais, 2009. 